\title{
Crown architecture of the ginger Alpinia scabra (Zingiberaceae) in a tropical submontane forest, Indonesia
}

\author{
Koichi TAKAHASHI \\ Department of Biology, Faculty of Science, Shinshu University, Matsumoto 390-8621, Japan. \\ E-mail: koichit@gipac.shinshu-u.ac.jp
}

\begin{abstract}
Crown architecture of a ginger, Alpinia scabra (Zingiberaceae), was studied on Mount Halimun in a tropical submontane forest in West Java, Indonesia. An aboveground shoot of A. scabra consists of one pseudostem and many leaves distributed along the pseudostem. The pseudostem is up to ca. $2 \mathrm{~m}$ long. The number of nodes per pseudostem increases, up to 25 , with increasing pseudostem length. Pseudostems of smaller A. scabra stand vertically, while those of larger A. scabra bend. On the contrary, the leaf surface is horizontally oriented, irrespective of the pseudostem angle at each node. The horizontal orientation of leaf surface is thought to be effective for capturing the most light per unit leaf area. The internode length decreases from the base of the pseudostem to the tip, i.e., the internode length decreases with increasing pseudostem length, accompanied with stem bending. The ontogenic changes of leaf size in large individuals of A. scabra show that leaf size increases from the base of the pseudostem to the mid-point of pseudostem, and levels off or slightly decreases thenceforth. Thus, leaves were small near the base, where pseudostems stood vertically, and increased in size with pseudostem bending. The combination of an erect pseudostem and small leaves near the base contributes to less vertical overlap of leaves there. The results of this study suggest that $A$. scabra distributes leaves for efficient light capture by adjusting the internode length, leaf angle, pseudostem angle, and leaf size along the pseudostem.
\end{abstract}

Key words: Alpinia scabra, crown architecture, tropical submontane forest, Zingiberaceae

\section{INTRODUCTION}

Zingiberaceae is one of the most dominant families of understory plants in tropical rain forests in Southeast Asia. Although Zingiberaceae is important for commercial use, there are few ecological studies of this family. Of those, Nishimura and Suzuki (2000) examined the spatial distribution of several ginger species (Zingiberaceae) in relation to edaphic conditions in a tropical submontane forest in Indonesia, and they discovered that the spatial segregation among the ginger species, probably caused by the interspecific differences in suitable edaphic conditions such as mesic-xeric conditions, is important for the maintenance of species diversity of the ginger species. These kinds of ecological studies elucidate the species maintenance of ginger.

Light deficiency is pronounced in understories, especially in tropical rain forests which have developed canopy stratification (Yoda, 1974). Thus, efficient light capture is important for the growth and survival of understory plants. For example, two understory palms, Licuala arbuscula Becc. and L. bintulensis Becc., construct their crowns in a way that increases light capture per plant by decreasing mutual shading among leaves within a crown (Takahashi \& Kohyama, 1997; Takenaka et al., 2001). A similar result was also reported for an understory herb in a temperate forest (Pearcy \& Yang, 1998). Therefore, the crown architecture of understory ginger species reflects selection pressure to increase light capturing efficiency (e.g., Valladares et al., 2002). The crown architecture of ginger species is simple. Stems of ginger species exist under the ground, and an aboveground shoot consists of one pseudostem and many leaves distributed along the pseudostem. Crown architecture of the aboveground shoot can be described by the internode length, the number and size of leaves, the angles of pseudostem and leaves. Therefore, these traits should be investigated to examine how ginger species develop their crowns in order to increase light capture.

Alpinia scabra (B1.) Backer is a dominant ginger species on the forest floor in tropical submontane forests in West Java, Indonesia (Nishimura \& Suzuki, 2000). Although Nishimura and Suzuki (2000) compared the crown allometry among several ginger species, including $A$. scabra, there are no studies that examined the crown architecture, including leaf display pattern, of $A$. scabra. Therefore, this study aims to describe the crown architecture of the understory ginger A. scabra. 


\section{MATERIALS AND METHODS}

\section{Study site}

This study was carried out in Mount Halimun National Park (644' S, $106^{\circ} 32^{\prime} \mathrm{E}, 1100 \mathrm{~m}$ above sea level), West Java, Indonesia. The annual mean rainfall, recorded at the office of the tea plantation near the study site during 1998 to 2002 , was $3869 \mathrm{~mm}$. The rainy season lasts from October to April, and monthly rainfall exceeds $300 \mathrm{~mm}$ during this period. The monthly mean temperatures were between $24^{\circ} \mathrm{C}$ and $31^{\circ} \mathrm{C}$ during 1998 to 1999 .

Two permanent plots, $100 \mathrm{~m} \times 100 \mathrm{~m}$ in area, were established on Mount Kendung in a tropical submontane forest (Suzuki et al., 1997, 1998). The numbers of tree species $>4.8 \mathrm{~cm}$ in diameter at breast height in the two plots were 116 and 103 species, and the total basal area was $36.3 \mathrm{~m}^{2} /$ ha and $35.4 \mathrm{~m}^{2} /$ ha. The maximum tree heights of the two plots were $54 \mathrm{~m}$ and $37 \mathrm{~m}$. Dominant species in the two plots were Altingia excelsa Noronha, Castanopsis acuminatissima A. DC. ex Hance., Schima wallichii Choisy and Quercus lineata Blume (Suzuki et al., 1997, 1998). Ten ginger species were found in the two plots. A. scabra was the most dominant species among them, and occupied ca. $90 \%$ of the total density of the ginger species. The densities of $A$. scabra were 5218 and 2718 shoots/ha in the two plots (Nishimura \& Suzuki, 2000).

\section{Field methods}

A. scabra is a small ginger species, up to ca. $2 \mathrm{~m}$ in pseudostem length. Simple-formed leaves are alternately distributed along a pseudostem (Fig. 1). A reproductive organ emerges on the top of the pseudostem in mature individuals (Fig. 1). Forty individuals of $A$. scabra were randomly selected outside the two permanent plots from $4^{\text {th }}$ to $7^{\text {th }}$, October 2003 . To describe the crown architecture of $A$. scabra, the internode length and the angle of pseudostem from the horizon at each node were measured. Leaf length and its angle from the horizon were also measured for all leaves of each A. scabra. Dead leaves were excluded from the measurements.

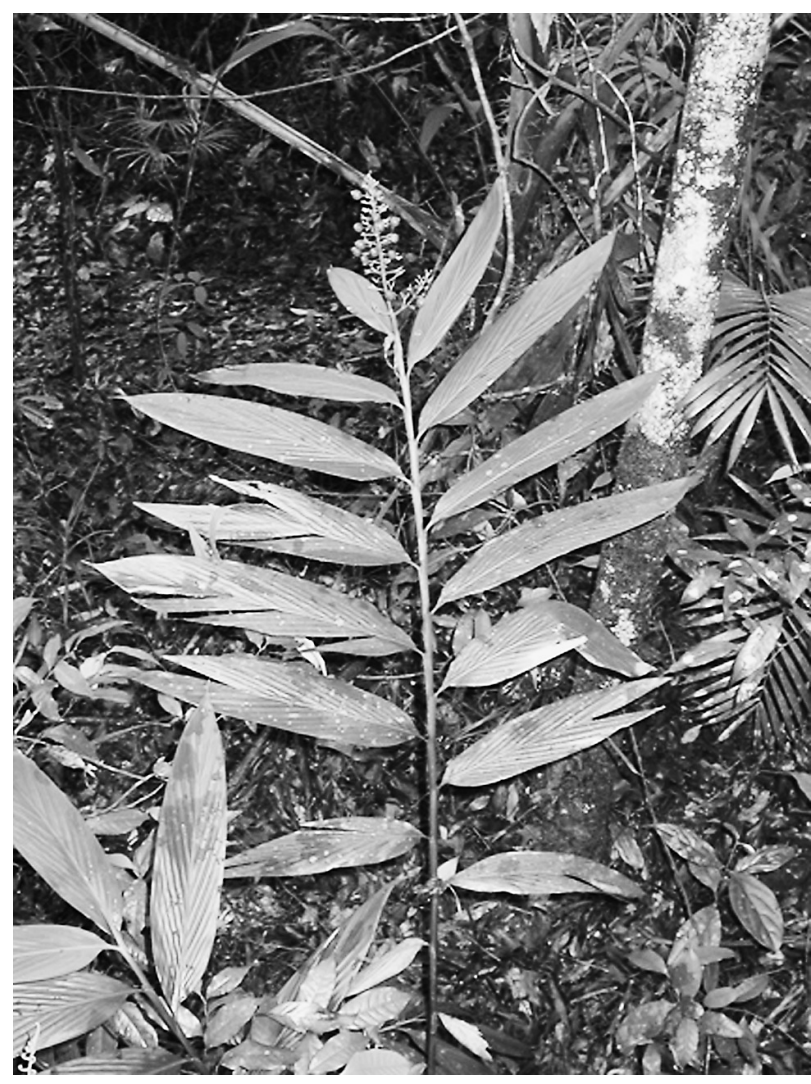

Fig. 1. A photo of Alpinia scabra in a tropical submontane forest, West Java, Indonesia. The reproductive organ is at the top of the pseudostem. 


\section{RESULTS}

The observed maximum number of nodes per pseudostem was 25, and the maximum pseudostem length was $183 \mathrm{~cm}$. The pseudostem lengths of $A$. scabra were highly correlated with the numbers of nodes per pseudostem (Pearson correlation coefficient $r=0.846, P<0.001, n=40$, Fig. 2). Therefore, in this study the size of $A$. scabra is represented by its number of nodes per pseudostem. This study shows the results of the crown-architectural parameters of $A$. scabra by dividing them into the three node classes: 5-11 nodes per pseudostem, 12-18 nodes per pseudostem and 19-25 nodes per pseudostem.

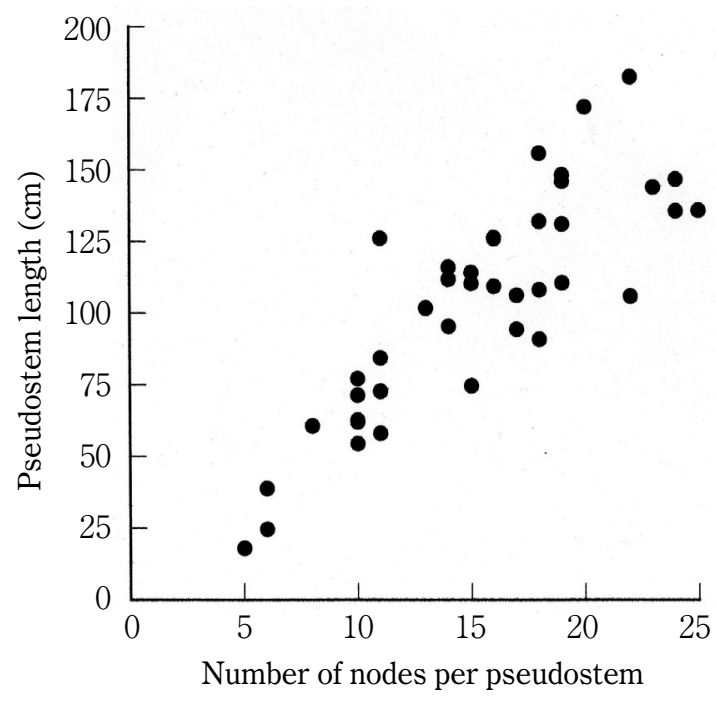

Fig. 2. The relationship between the pseudostem length and the number of nodes per pseudostem of Alpinia scabra in a tropical submontane forest, West Java, Indonesia.

The angle of pseudostem from the horizon for each $A$. scabra decreased with increasing node order from the base (Fig. 3), i.e., the pseudostem of $A$. scabra stood vertically near the base, and the pseudostem progressively bent as plant size increased. On the contrary, the angles of leaves from the horizon were nearly zero degrees from the base of the pseudostem to the tip in each A. scabra (Fig. 4). Thus, the leaf surface was horizontally oriented, irrespective of the pseudostem angle.

The leaf length increased from the base of the pseudostem to the node-order ca. 12, and then leveled off or slightly decreased thenceforth (Fig. 5). In the comparison of leaf length among the three node classes, the leaf lengths of $A$. scabra of the larger size classes were slightly greater at any node order between node order 1 to 11 (ANCOVA with node order as a covariate, $F_{2,363}=6.23, P<0.01$, Fig. 5) and between node order 12 to 18 (ANOVA, $F_{1,150}=5.16, P<0.05$, Fig. 5b, c). Although the internode length dropped at the node-order 2 in many individuals of $A$. scabra, the internode length for each $A$. scabra tended to decrease with increasing node order (Fig. 6). In the comparison of internode length among the three node classes, the internode lengths of $A$. scabra at larger size classes were slightly greater at any node order between node order 1 to 11 (ANCOVA with node order as a covariate, $F_{2,412}=25.9, P<0.01$, Fig. 6 ) and between node order 12 to 18 (ANOVA, $F_{1,187}=16.0, P<0.001$, Fig. $\left.6 \mathrm{~b}, \mathrm{c}\right)$. These results indicate that larger $A$. scabra had larger leaves and longer internodes at any node order.

\section{DISCUSSION}

Pseudostems of smaller A. scabra stood vertically, while those of larger A. scabra had arched and planer forms. In shaded understory conditions, suppressed saplings of tree species often show flat-shaped crowns. This crown shape is formed by greater elongation of lateral branches than trunk height growth, and is considered to be advantageous for survival in shaded conditions, because it creates less self-shading within a crown (Kohyama, 1980; Takahashi, 1996). Not only the growth of lateral branches but also the stem bending reduces self-shading (Canham, 1988; King, 2001). Therefore, the arched and planer form of A. scabra is thought to be effective for light capture without the self-shading within a crown. Valladares $e t$ al. 

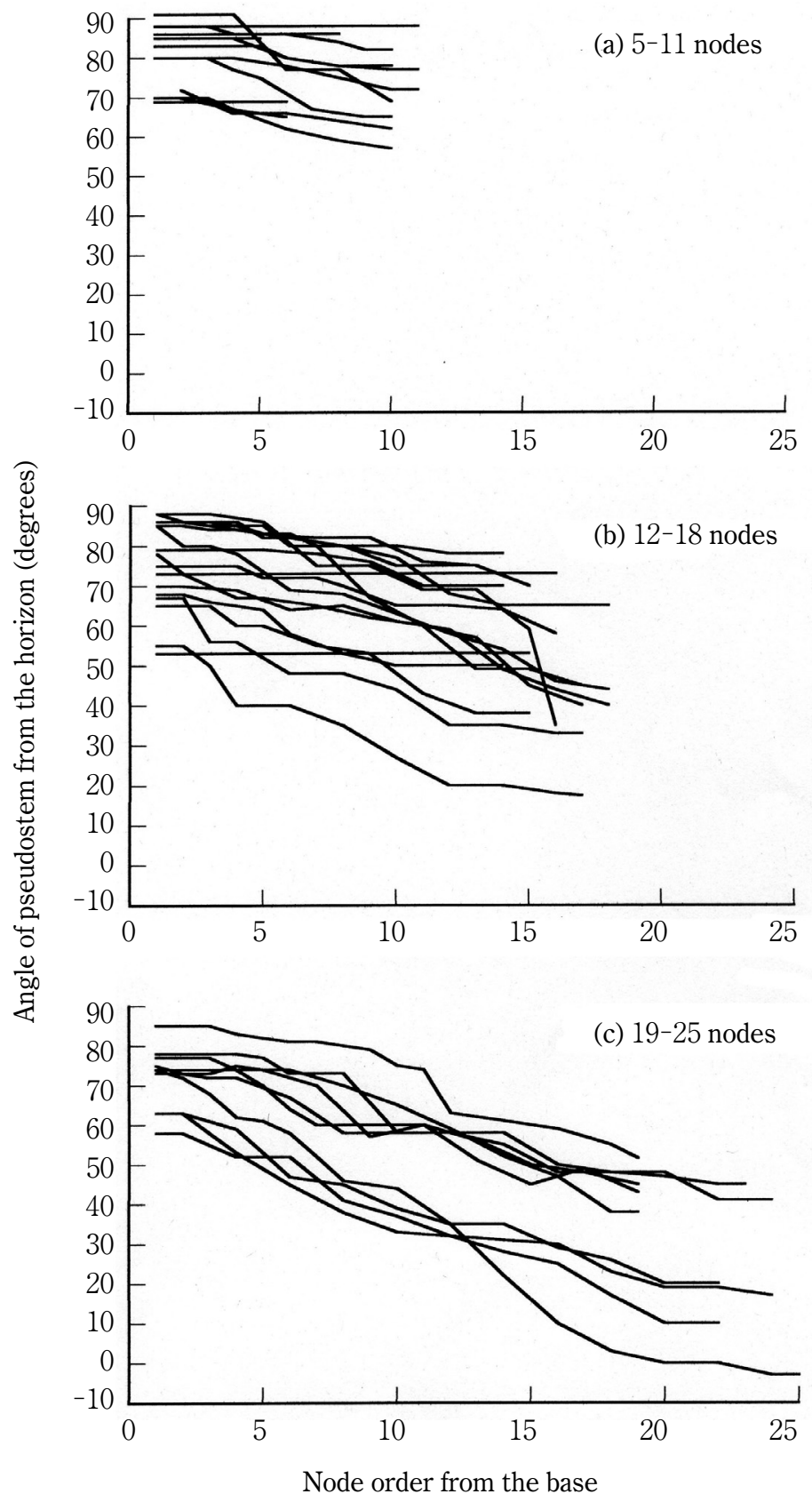

Fig. 3. The relationship between the angle of pseudostem from the horizon at each node and the node order from the base of the pseudostem. Each line indicates one individual Alpinia scabra. The plants were divided into three node classes: (a) 5-11 nodes per pseudostem, (b) 12-18 nodes per pseudostem and (c) 19-25 nodes per pseudostem. 

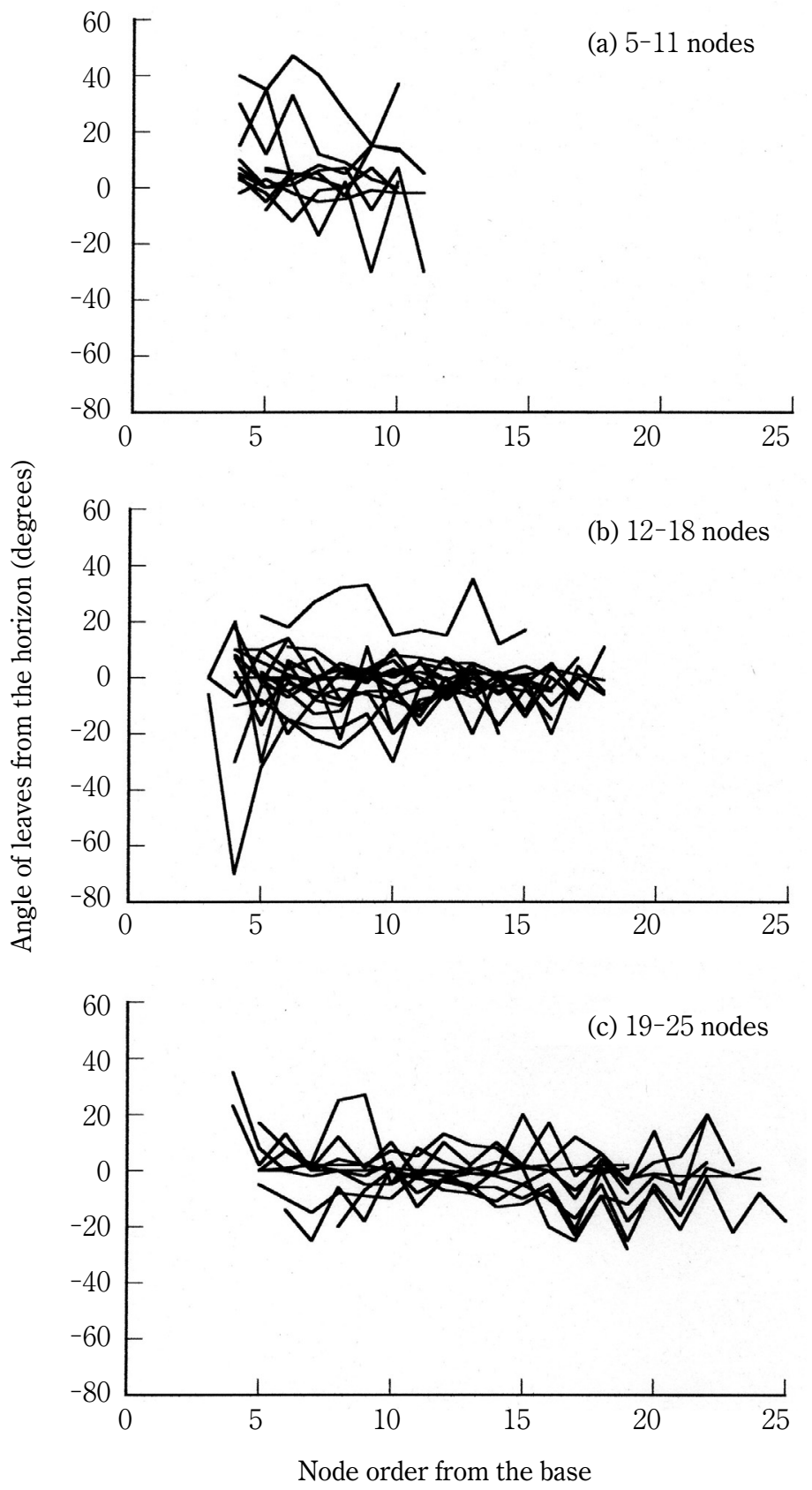

Fig. 4. The relationship between the angle of leaves from the horizon and the node order from the base of the pseudostem. Classification is the same as that of Figure 3. 

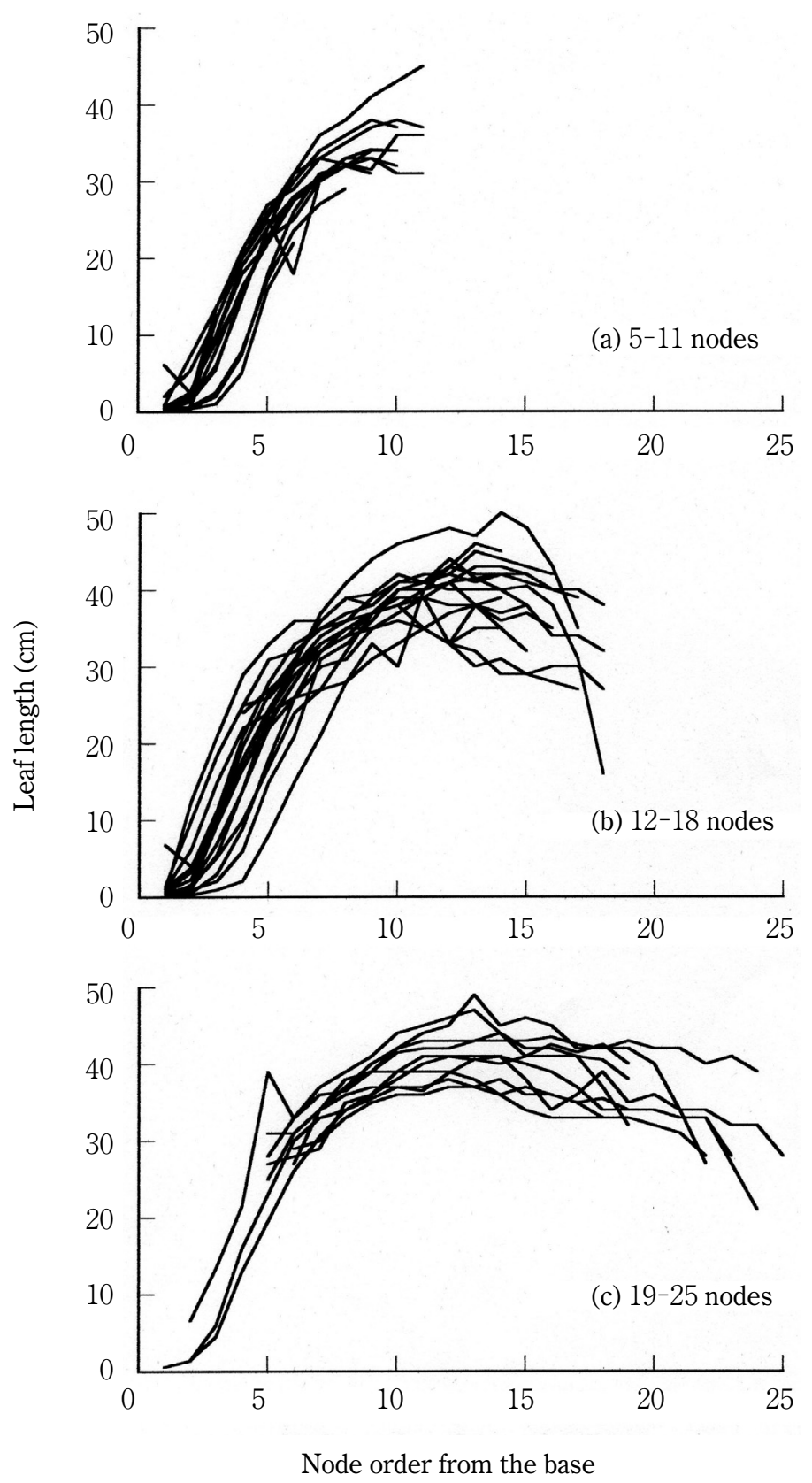

Fig. 5. The relationship between the leaf length and the node order from the base of the pseudostem. Classification is the same as that of Figure 3. 

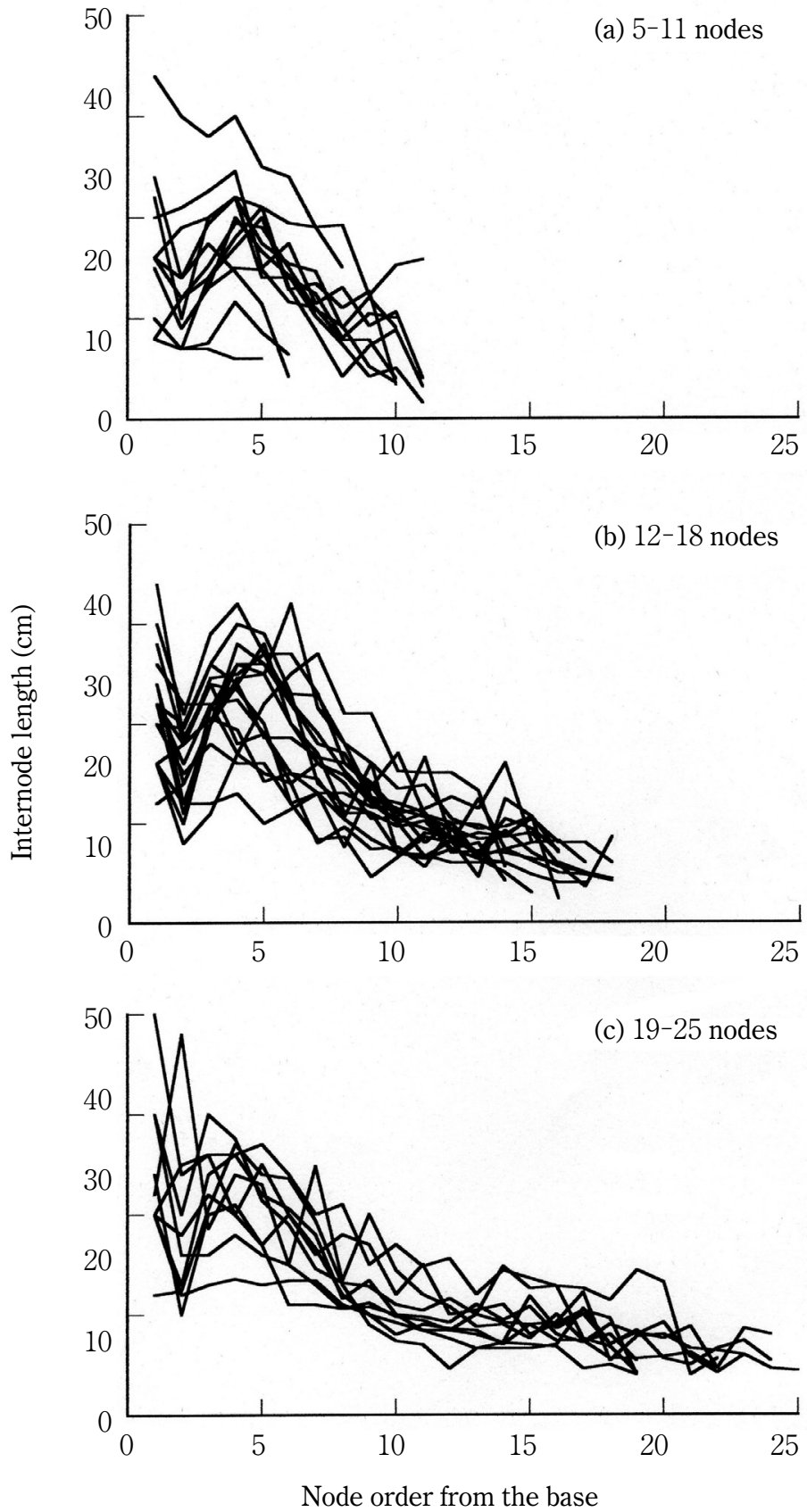

Fig. 6. The relationship between the internode length and the node order from the base of the pseudostem. Classification is the same as that of Figure 3. 
(2002) also pointed out the importance of arched stem for the avoidance of self-shading for another ginger, Renealmia cernua (Sw.) Macbr. In addition, leaves of A. scabra were small near the base of the pseudostem that stood vertically. The combination of the erect pseudostem and small leaves contributes to less vertical overlap of leaves near the base.

The leaf surfaces of A. scabra were horizontally oriented, irrespective of the pseudostem angle. The optimal orientation of leaf surface for carbon gain is to face the direction that the most light resource comes from (Ackerly \& Bazzaz, 1995). Generally, the radiance at the zenith is assumed to be two or three times greater than that at the horizon in the standard overcast sky model of diffuse light distribution (cf. Monteith \& Unsworth, 1990). Although the distribution of canopy openings affects the zenith angle dependency of light intensity on the forest floor, more light comes from the upper directions in understory conditions (e.g., Chazdon, 1985). Therefore, the horizontal orientation of leaf surface in A. scabra maximizes light capture per unit leaf area.

The internode length of $A$. scabra decreased with increasing pseudostem length, which is associated with the bending of the pseudostem. The short internode length at the top of pseudostem enabled the compact formation of leaves in close proximity to neighboring leaves, so that the short internode length reduces the force of the bending on the pseudostem, caused by the weight of pseudostem and leaves. If the internode length does not decrease with node order, a thicker pseudostem is necessary to resist the bending force, which results in the high allocation of carbon to pseudostem for the construction of a thick and long pseudostem. Therefore, the compact formation of leaves probably increases the light capture per unit biomass of shoot. Thus, this study suggests that $A$. scabra distributes leaves for efficient light capture by adjusting the internode length, leaf angle, pseudostem angle, and leaf size along the pseudostem. These crown-architectural traits are probably related to the plant's adaptation to understory environments with a shortage of light.

ACKNOWLEDGEMENTS I am grateful to Muhammad Amir for his assistance in the field. Thanks are also due to the staff of the Research and Development Center for Biology, Indonesian Institute of Science for their kindly support. This study was conducted under the permission of the Indonesian Institute of Science (LIPI). The field study was financially supported by a grant from the Ministry of Education, Culture, Sports, Science and Technology, Japan (No. 14255003).

\section{REFERENCES}

Ackerly, D. D. \& Bazzaz, F. A. 1995. Seedling crown orientation and interception of diffuse radiation in tropical forest gaps. Ecology 76: 1134-1146.

Canham, C. D. 1988. Growth and canopy architecture of shade-tolerant tree: response to canopy gaps. Ecology 69: 786-795.

Chazdon, R. L. 1985. Leaf display, canopy structure, and light interception of two understory palm species. American Journal of Botany 72: 1493-1502.

King, D. A. 2001. Stem orientation is related to growth rate, leaf dimensions, and the deciduous habit in temperate forest saplings. Canadian Journal of Botany 79: 1282-1291.

Kohyama, T. 1980. Growth pattern of Abies mariesii saplings under conditions of opengrowth and suppression. Botanical Magazine, Tokyo 93: 13-24.

Monteith, L. L. \& Unsworth, M. 1990. Principles of Environmental Physics. 2nd edition. Arnold, London.

Nishimura, T. B. \& Suzuki, E. 2000. Spatial distributions of ginger species at tropical submontane forest floor. Tropics 9: 103-116.

Pearcy, R. W. \& Yang, W. 1998. The functional morphology of light capture and carbon gain in the Redwood forest understorey plant Adenocaulon bicolor Hook. Functional Ecology 12: 543-552.

Suzuki, E., Yoneda, M., Simbolon, H., Muhidin, A. \& Wakiyama, S. 1997. Establishment of two 1-ha permanent plots in Gunung Halimun National Park for study of vegetation structure and forest dynamics. In: Research and Conservation of Biodiversity in Indonesia. Vol. II. The Inventory of Natural Resources in Gunung Halimun National Park. (LIPI, JICA, \& PHPA, eds.), Pp. 36-55. LIPI, JICA, and PHPA, Bogor.

Suzuki, E., Yoneda, M., Simbolon, Fanani, Z., Nishimura, T. \& Kimura, M. 1998. Monitoring of vegetation changes on permanent plots in Gunung Halimun National Park. In: Research and Conservation of Biodiversity in Indonesia. Vol. IV. Gunung Halimun: The Last Submontane Tropical Forest in West Java, (Simbolon, H., Yoneda, M. \& Sugardjito, J., eds.), Pp. 60-81. LIPI, JICA, and PHPA, Bogor.

Takahashi, K. 1996. Plastic response of crown architecture to crowding in understorey trees of two co-dominating conifers. 
Annals of Botany 77: 159-164.

Takahashi, K. \& Kohyama, T. 1997. Crown architecture of two understory palm species of the genus Licuala in a tropical rain forest. Plant Species Biology 12: 35-41.

Takenaka, A., Takahashi, K. \& Kohyama, T. 2001. Optimal leaf display and biomass partitioning for efficient light capture in an understorey palm, Licuala arbuscula. Functional Ecology 15: 660-668.

Valladares, F., Skillman, J. B. \& Pearcy, R. W. 2002. Convergence in light capture efficiencies among tropical forest understory plants with contrasting crown architectures: a case of morphological compensation. American Journal of Botany 89: 1275-1284.

Yoda, K. 1974. Three-dimensional distribution of light intensity in a tropical rain forest of West Malaysia. Japanese Journal of Ecology 24: 247-254.

Received $9^{\text {th }}$ Dec. 2003

Accepted $10^{\text {th }}$ May. 2004 